\title{
Ultrasound for Critical Care Physicians: Connecting Disparate Symptoms
}

An 18-year-old woman was recently diagnosed with non-ACTH-Mediated Cushing syndrome, now with a complaint of mild shortness of breath.

Her cardiac exam showed normal sinus rhythm at 84 beats per minute and blood pressure of $130 / 80 \mathrm{mmHg}$. Her mitral first heart sound was slightly accentuated, but the pulmonic sound was normal. Grade-I diastolic murmur was heard over the mitral area. Opening snap was absent. Lungs were clear and chest radiograph showed slight cardiomegaly. She had multiple freckles on his face and trunk and along the vermillion border of the lips.

An ultrasound of the heart was performed (Figure 1).

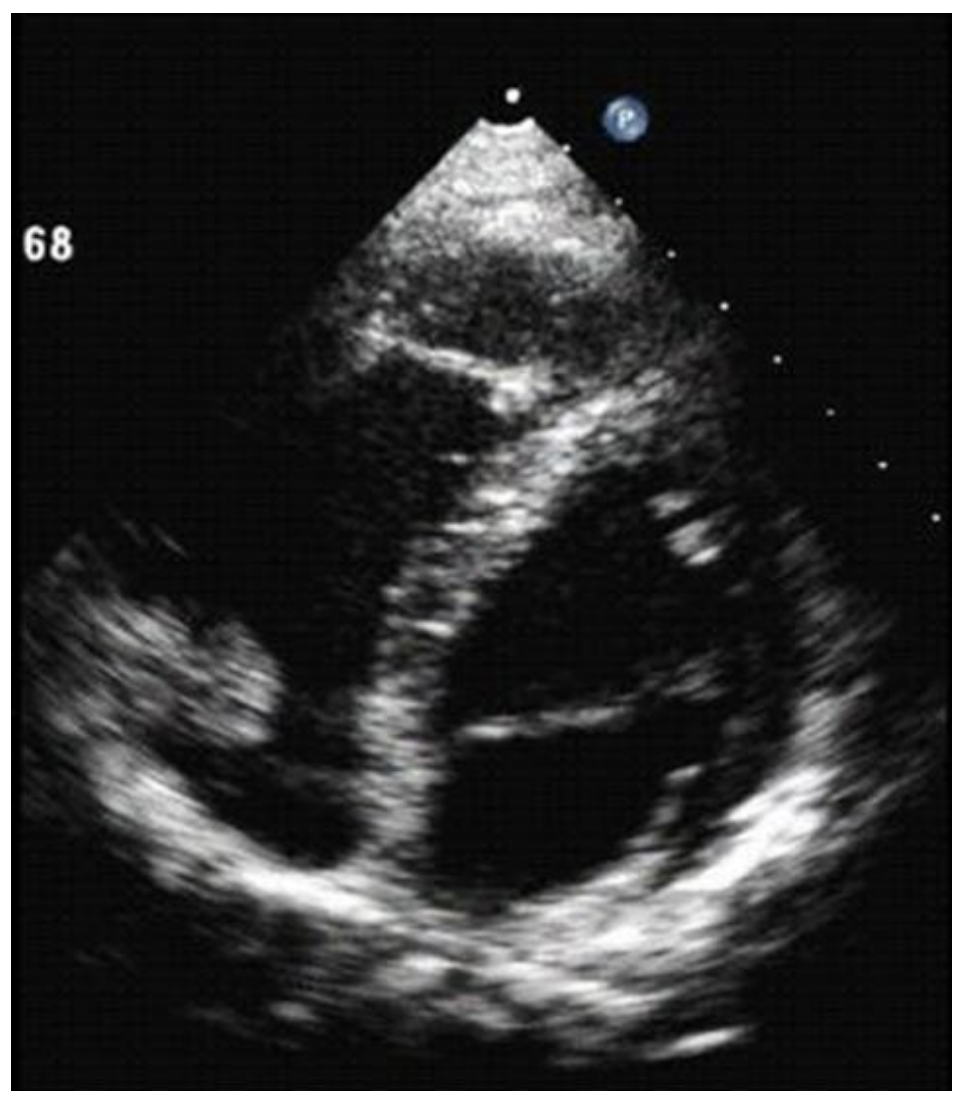

Figure 1. Four chamber view of the heart.

Which of the following is the likely diagnosis?

1. Brugada syndrome

2. Carney syndrome

3. Gotway syndrome

4. Jervell and Lange-Nielsen syndrome

5. Peutz-Jeghers syndrome 


\section{Correct! \\ 2. Carney syndrome}

The ultrasound of the heart shows a mass in the right atrium (Figure 2).

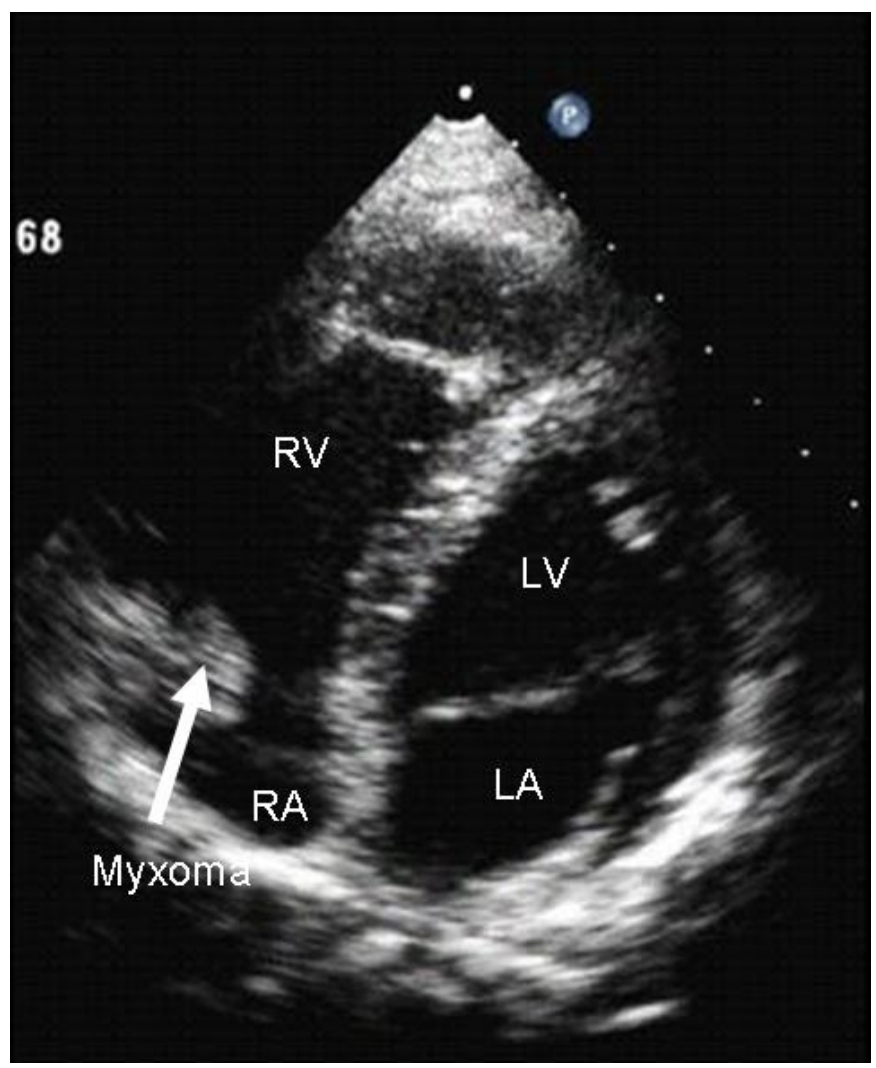

Figure 2. Ultrasound of the heart showing a mass characteristic of a myxoma.

An intracardiac mass attached to the interatrial septum and / or anterior leaflet of the mitral valve is characteristic of a myxoma.

Peutz-Jeghers syndrome, also known as hereditary intestinal polyposis syndrome, is characterized by the development of benign hamartomatous polyps in the gastrointestinal tract and hyperpigmented macules on the lips and oral mucosa. The Brugada syndrome is a genetic disease that is characterized by abnormal electrocardiogram (ECG) findings and an increased risk of sudden cardiac death. The Jervell and Lange-Nielsen syndrome (JLNS) is a congenital long QT sydrome associated with congenital deafness. To my knowledge there is no Gotway syndrome described yet.

The patient also has spotty skin pigmentation. A multiple neoplasia syndrome characterized by spotty skin pigmentation, cardiac and other myxomas, endocrine tumors, and other tumors was described by J. Aidan Carney (Figure 3) and colleagues from the Mayo Clinic in the mid-1980's (1). 


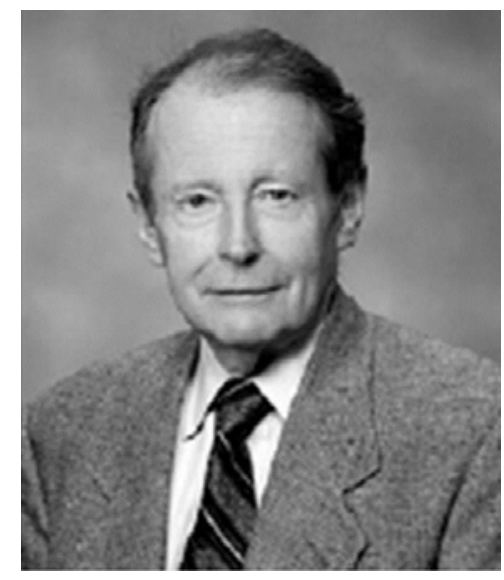

Figure 3. J. Aidan Carney

Carney syndrome, also known as Carney complex (CNC), is an autosomal dominant disorder that exists in two forms (2). One form can be mapped to chromosome 17, and the other, to chromosome 2. The chromosome 17 form, designated Carney complex type I, is due to mutations in the cAMP-dependent protein kinase type I-alpha (PRKAR1A) gene. Further research is needed to delineate the exact genetic mutations on chromosome 2. Most of the cases of Carney syndrome $(70 \%)$ are familial.

Small, brown to black, non or slightly elevated, round or irregular skin pigmentations or blue nevi (large, blue to black, domed lesion) are observed primarily in the face, eyelids, ears, and borders of the lips (2). These tend to fade with age, usually after the fourth decade of life. Heart myxomas (53\%) occur multicentrically, and in any, or all, cardiac chambers; skin myxomas (33\%) are detected in the eyelid, the external ear canal, the nipple, the oropharynx, the female genital tract and the female pelvis. Breast myxomas are often bilateral and present in more than $70 \%$ of adult women with Carney syndrome. Endocrine lesions in Carney syndrome include testicular neoplasms (33\%), primary pigmented nodule adrenocortical disease (PPNAD) (26\%), growth hormone (GH) and prolactin-producing pituitary tumors (14\%) and thyroid cancer (5\%).

Michael B. Gotway, MD Department of Radiology Mayo Clinic Arizona

\section{References}

1. Carney JA, Gordon H, Carpenter PC, Shenoy BV, Go VL. The complex of myxomas, spotty pigmentation, and endocrine overactivity. Medicine (Baltimore). 1985;64(4):270-83. [PubMed]

2. Schwartz RA, Centurion SA, Cruz MA. Carney sydrome. Medscape. Available at: http://emedicine.medscape.com/article/1097150-overview\#a0101 (accessed 9/5/13). 